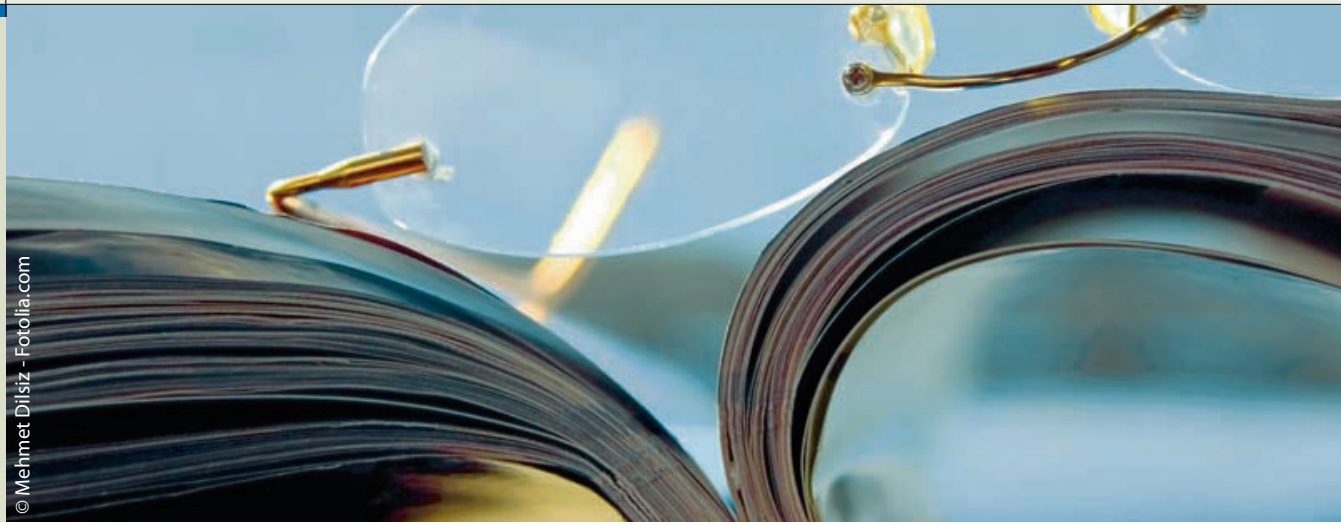

\section{4-Jähriger mit Halsschmerzen: Was färbte die Zunge schwarz?}

Ein 24-jähriger Mann kam mit Halsschmerzen in die Sprechstunde. Besonders beunruhigte inn aber eine Schwarzfärbung am Zungengrund.

Megen eines Infekts der oberen Luftwege hatte der Patient in der vorangegangenen Woche Ciprofloxacin und Doxycyclin eingenommen. Er war Nichtraucher und benutzte auch keinen Kautabak. Auch nahm er keine wismuthaltigen Medikamente ein.

Bei der Untersuchung erkannte man weißliche Beläge der Zunge und eine schwarze Verfärbung des Zungengrundes. Fieber, Lymphknotenvergrößerungen oder eine Hepatosplenomegalie wurden nicht festgestellt. Schnelltests auf Streptokokkenantigen und Mononukleose fielen negativ aus. Im Rachenabstrich konnte Candida albicans nachgewiesen werden.
Die schwarze Haarzunge (Lingua villosa nigra) tritt auf in Anwesenheit chromogener Mikroorganismen, zum Beispiel Candida albicans und bei Verwendung bestimmter Medikamente, zum Beispiel Doxycylin oder Wismut. Allerdings ist nicht bekannt, ob Doxycyclin und Candida albicans im Hinblick auf die Verfärbung der Zungenpapillen synergistisch wirken. Man nimmt an, dass es zunächst zu einer Proliferation der filiformen Zungenpapillen kommt, die mit porphyrinproduzierenden chromogenen Bakterien oder Hefen schwarz eingefärbt werden. Doxycylin wurde abgesetzt und der Patient über kurze Zeit hinweg mit Fluconazol behandelt. Die schwarze Verfärbung

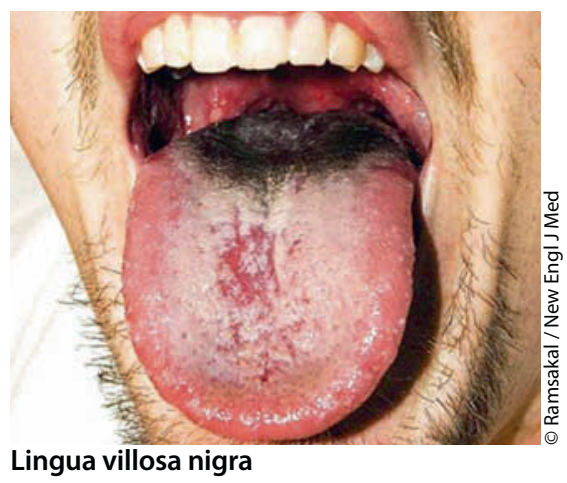

und die haarige Oberfläche der Zunge verschwanden innerhalb von drei Tagen.

Mit der sorgfältigen Erhebung der Anamnese und der richtigen Blickdiagnose konnten in diesem Fall unnötige Maßnahmen vermieden und dem Patienten rasch geholfen werden.

H. S. FüeßI

Ramsakal A, Mangat L. Lingua villosa nigra. New Engl J Med 2010; 357: 2388

\title{
Therapie mit fotosensibilisierenden Substanzen: Hier können Pulsoximeter gefährlich sein
}

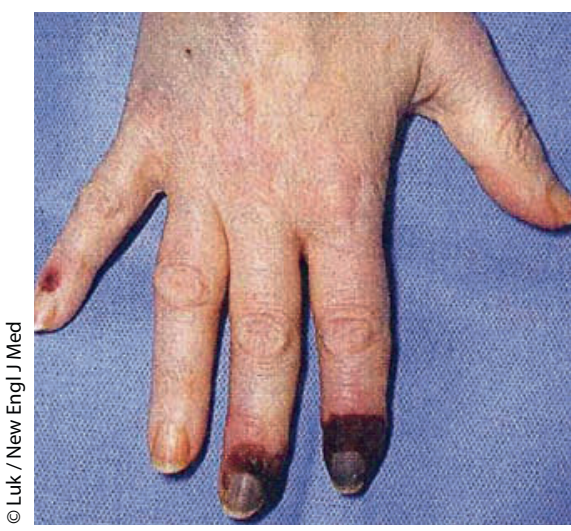

Das Pulsoximeter hat zu Nekrosen an den Fingerkuppen geführt.
$\mathrm{D}$ ie Sauerstoffsättigung einer 58-jährigen Frau, die sich zur Behandlung von Lymphknotenmetastasen eines Mammakarzinoms mit der fotosensibilisierenden Substanz Foscan im Krankenhaus befand, wurde mittels Pulsoximeter überwacht. An den Fingerkuppen des zweiten und dritten Fingers rechts, wo das Pulsoximeter angebracht war, kam es zu einer Gangrän.

Die Wellenlänge des Lichts, das in üblichen Pulsoximetern verwendet wird, liegt nahe an der Wellenlänge des Lichts für die Aktivierung von Foscan ${ }^{\circ}$. Diese Fotoaktivierung führt zu einer ausge- dehnten Gewebedestruktion. Dieses Risiko ist sicher nicht allgemein bekannt und sollte dadurch vermieden werden, dass man Pulsoximeter immer nur möglichst kurzzeitig anwendet und häufig den Finger wechselt. Leider erfahren wir nicht, ob es in diesem Fall eine juristische Auseinandersetzung gab und wie diese ausging.

H. S. FüeßI 